\title{
Frequency of Extended-spectrum $\beta$-lactamase (ESBL) and AmpC $\beta$-lactamase Genes in Escherichia coli and Klebsiella pneumoniae over a Three-year Period in a University Hospital in Korea
}

\begin{abstract}
Xue Min Li, M.D. ${ }^{1}$, Sook-Jin Jang, M.D. ${ }^{1,2}$, Il Kwon Bae, Ph.D ${ }^{3}$, Geon Park, M.D. ${ }^{2}$, Young Sook Kim, M.D. ${ }^{4}$, Jong Hee Shin, M.D. ${ }^{5}$, Dae Soo Moon, M.D. ${ }^{2}$, and Young Jin Park, M.D. ${ }^{2}$

Research Center for Resistant Cells ${ }^{1}$, and Department of Laboratory Medicine², Chosun University College of Medicine, Gwangju; Department of Laboratory Medicine and Research Institute of Bacterial Resistance ${ }^{3}$, Yonsei University College of Medicine, Seoul; Department of Radiology ${ }^{4}$, Chosun University College of Medicine, Gwangju; Department of Laboratory Medicine ${ }^{5}$,

Chonnam National University College of Medicine, Gwangju, Korea
\end{abstract}

Background : The aim of this study was to determine the yearly prevalence and genotype distribution of extended-spectrum $\beta$-lactamase (ESBL)-producing Escherichia coli and Klebsiella pneumoniae collected over a 3-yr period in Gwangju, Korea.

Methods : Clinical isolates of E. coli and K. pneumoniae collected at Chosun University Hospital from September 15, 2005 to September 14, 2008 were evaluated. Antimicrobial susceptibility testing was performed using the Vitek II system (bioMérieux, USA) and agar dilution methods. Screening for ESBL and AmpC $\beta$-lactamase genes was performed using PCR amplification of plasmid DNA followed by direct sequencing of the PCR products.

Results : The percentage of ESBL-producing isolates was $12.6 \%(196 / 1,550)$ for E. coli and $26.2 \%(294 / 1,121)$ for K. pneumoniae. The ESBL gene sequencing results showed that the most prevalent ESBL types were CTX-M (93.5\%) and SHV (12.9\%) in E. coli, and SHV (73.2\%) and CTX$\mathrm{M}(46.3 \%)$ in K. pneumoniae. The most common ESBL in E. coli was CTX-M-15-like, followed by CTX-M-14-like, SHV-2a-like, and SHV-12-like. The most prevalent ESBL type in K. pneumoniae was SHV-12, followed by CTX-M-14-like and CTX-M-15-like. Fifty-one percent (21/41) of ESBL-producing K. pneumoniae with ESBL types verified by sequencing also had DHA-1-like AmpC $\beta$-lactamases. However, none of the ESBL-producing E. coli was positive in the AmpC $\beta$-lactamase PCR analysis.

Conclusions : In this study, the most common types of class A ESBLs identified were CTX-M-15like in E. coli and SHV-12-like in K. pneumoniae. (Korean J Lab Med 2010;30:616-23)

Key Words : $\beta$-lactamase, Prevalence, Escherichia coli, Klebsiella pneumonia

\section{서 론}

Extended-spectrum $\beta$-lactamase (ESBL) 생성 그람음성

\section{Received: March 31, 2010}

Manuscript No : KJLM10-059

Revision received: September 6, 2010

Accepted: October 14, 2010

Corresponding author: Sook-Jin Jang, M.D.

Department of Laboratory Medicine, Chosun University

College of Medicine, 588 Seoseok-dong, Dong-gu, Gwangju

501-717, Korea

Tel : +82-62-220-3272, Fax : +82-62-232-2063

E-mail : sjbjang@chosun.ac.kr

*This study was supported by a grant from the Clinical Medicine Research Institute at Chosun University Hospital (2006).

ISSN 1598-6535 (C) The Korean Society for Laboratory Medicine
장내세균(Enterobacteriaceae)은 다제내성을 보여 감염되면 마땅한 치료약제를 선택하기 어렵고 환자의 입원기간이 길어질 수 있으므로 병원의 환자 진료뿐만 아니라 국민 건강 보건의 측 면에서도 중요한 균이다. 또한 국내에서 분리되는 $\mathrm{ESBL}$ 생성주 는 플라스미드 매개성 AmpC $\beta$-lactamase (plasmid-mediated AmpC $\beta$-lactamase, PABL)를 동시에 생성하는 경우가 많다[1]. AmpC 효소의 유전자는 Enterobacter, Citrobacter, Serratia, Pseudomonas와 같은 세균의 염색체에 자연적으로 존재하였는데 최근 이들이 플라스미드를 통해 원래 chromoso$\mathrm{mal} \mathrm{AmpC}$ 가 결여되어 있는 균들인 Klebsiella나 Salmonella, Proteus mirabilis 등의 세균들에 들어가 이런 균들에서 검출되 는 경우가 증가되고 있다[2]. 
$\mathrm{ESBL}$ 유전형의 분포 및 변화추이를 추적한 결과는 $\mathrm{ESBL}$ 의 전파 양상이나 돌발 감염 가능성 등을 숙고하기 위한 기초자료 이다. 각 유전형의 특성과 분포 및 변화추이에 대한 자료가 축 적되면 $\mathrm{ESBL}$ 생성균의 전파를 막기 위한 적절한 대응 전략 수 립에 유용할 것이다. 또한 환자 진료지침과 다제내성균의 전파 억제를 위한 보건 정책을 수립하는 데도 도움이 되기 때문에 이 러한 자료들을 꾸준히 조사할 필요가 있다.

국내의 $\mathrm{ESBL}$ 생성 그람음성 장내세균주에 대해서는 여러 연 구가 진행되어 왔으며 ESBL 생성 Escherichia coli와 Klebsiella pneumoniae균의 빈도와 유전형에 대해 한국의 전반적 인 현황을 파악한 연구들은 보고되어 왔으나, 한 병원에서 다년 간 수집된 검체를 대상으로 연구한 논문은 드물다. 본 연구에서 는 광주의 조선대학교 병원에서 3 년간 분리된 $E$. coli와 $K$. pneumoniae 균주에 대하여 ESBL의 보유율과 유전형의 분포 를 조사하였다. 또한 본원에서 분리된 $\mathrm{ESBL}$ 생성 $\mathrm{E}$. coli와 $K$. pneumoniae 균주들의 AmpC $\beta$-lactamase 유전자 보유 현황 을 함께 조사하였다.

\section{재료 및 방법}

\section{1. 균주의 수집}

2005년 9월 15일부터 2008년 9월 14일까지 3년간 조선대학 교병원 진단검사의학과 미생물 검사실에 세균배양검사가 의뢰 되어 배양된 E. coli와 K. pneumoniae를 무작위로 수집하여 저장해 두었다. 그중 Vitek II system (bioMérieux, Durham, $\mathrm{NC}, \mathrm{USA}$ )에서 $\mathrm{ESBL}$ 양성 결과를 보인 $E$. coli 46주와 $K$. pneumoniae 54주를 무작위로 선택하여 검사대상으로 하였다. $\mathrm{ESBL}$ 양성균의 빈도와 분리된 검체를 조사하기 위한 자료분석 은 같은 기간 중 배양된 E. coli 1,550주와 $K$. pneumoniae 1,121 주의 Vitek II system의 검사결과를 조회하여 분석하였 다. 동일 환자에서 반복 분리된 균주는 수집 및 분석 대상에서 제외하였다.

\section{2. 균주의 동정 및 항균제 감수성 검사}

균주의 동정 및 항균제 감수성 검사는 Vitek II ID-GNI Kit (bioMérieux)와 Vitek AST-N017이나 AST-N056 Kit (bioMérieux)에 균을 접종한 후, Vitek II system (bioMérieux)을 이용하여 제조사의 지침에 따라 시행하였다. Vitek II system의 Advanced Expert System soft ware version (VT2-R03.01)에
의해 판독된 결과를 사용하였다. 항균제 감수성 양상과 $\mathrm{ESBL}$ 양성률은 Vitek II system의 검사 결과 자료로 분석하였다. $\mathrm{ESBL}$ 를 생성하는 E. coli와 K. pneumoniae 균주들의 항균제 최소억제농도(minimum inhibitory concentration, $\mathrm{MIC}$ )는 CLSI 한천희석법으로 측정하였다[3]. 시험 항균제로는 cefoxitin (Sigma Co., St. Louis, MO, USA), cefotaxime (Sigma Co.), ceftazidime (Hanmi Pharm. Co. Ltd., Seoul, Korea) 을 사용하였고 E. coli ATCC 25922를 대조균주로 사용하였다.

\section{3. 분자생물학적 방법에 의한 내성 유전형 확인}

Vitek II system에서 ESBL 양성 결과를 보인 균주는 모두 $\mathrm{ESBL}$ 유전자에 대한 $\mathrm{PCR}$ 검사를 시행하였고 $\mathrm{PCR}$ 에 양성인 균주는 직접염기순서분석법으로 $\mathrm{ESBL}$ 유전형을 조사하였다. $\mathrm{ESBL}$ 및 $\mathrm{AmpC} \beta$-lactamase 유전자를 찾기 위해서 각 유전 자들에 특이적인 primer를 이용하여 PCR을 진행하였다(Table 1)[4-8]. AmpC $\beta$-lactamase 유전자에 대한 PCR 검사는 국내 에서 흔히 분리된 것으로 알려져 있는 $\mathrm{DHA}$ 와 $\mathrm{CMY}-1, \mathrm{CMY}-$ 2형에 대해 시행하였다[9].

Plasmid Extraction Kit (Bioneer, Daejeon, Korea)를 사 용하여 세균의 플라스미드 DNA를 추출하였다. 플라스미드 DNA 에 오염되어 있는 염색체성 DNA를 제거하기 위하여 PlasmidSafe ATP-Dependent DNase kit (EPICENTRE Biotechnologies, Madison, WI, USA)를 사용하였다. AccuPower $\mathrm{PCR}$ PreMix (Bioneer)에 플라스미드 DNA $2 \mu \mathrm{L}$ 와 각 유전자 에 특이적인 primer를 10 pmole씩 넣고 증류수를 혼합하여 $20 \mu \mathrm{L}$ 의 PCR 반응액을 만들었다. 각 유전자의 PCR은 Gene Amp PCR System 9600 (Perkin-Elmer Centus Co., Norwalk, CT, USA)을 이용하여 시행하였다.

$\mathrm{ESBL}$ 유전자 PCR 산물을 염기순서분석하여 유전자형을 확 인하기 위해 Big Dye Terminator Cycle Sequencing Kit와 ABI PRISM 3730 DNA analyzer (PE Applied Biosystems, Foster, CA, USA)를 이용하는 Solgent 회사(Solgent Co., Daejeon, Korea)에 염기순서분석을 의뢰하였다.

\section{결 과}

\section{ESBL 양성률}

조사기간 배양된 E. coli와 K. pneumoniae 균의 ESBL 양 성률을 Vitek II system의 ESBL 검사 결과로 살펴보면 E. coli 
Table 1. Primers used for detection and sequencing of ESBL and AmpC $\beta$-lactamase by using PCR

\begin{tabular}{|c|c|c|c|c|}
\hline Target gene & Primer name & Primer sequence $\left(5^{\prime}-3^{\prime}\right)$ & Product size (bp) & Reference \\
\hline \multirow[t]{2}{*}{ blaSHV } & SHV-F & GGGTTATTCTTATTTGTCGCT & 929 & {$[4]$} \\
\hline & SHV-R & TAGCGTTGCCAGTGCTCG & & \\
\hline \multirow[t]{2}{*}{ blaCTX-M-1 cluster } & CTX-1-un-F & SCSATGTGCAGYACCAGTAA & 543 & [5] \\
\hline & CTX-1-un-R & CCGCRATATCRTTGGTGGTG & & \\
\hline \multirow[t]{2}{*}{ blaCTX-M-1 cluster } & CTX-1-gr-F & CCCATGGTTAAAAAATCACTG & 891 & {$[6]$} \\
\hline & CTX-1-gr-R & CCGTTTCCGCTATTACAAAC & & \\
\hline \multirow[t]{2}{*}{ blaCTX-M-9 cluster } & CTX-M-9-F & GTGACAAAGAGAGTGCAACGG & 856 & {$[7]$} \\
\hline & CTX-M-9-R & ATGATTCTCGCCGCTGAAGCC & & \\
\hline \multirow[t]{2}{*}{ blaGES/IBC } & GES/IBC-F & GTTAGACGGGCGTACAAAGATAAT & 903 & [8] \\
\hline & GES/IBC-R & TGTCCGTGCTCAGGATGAGT & & \\
\hline \multirow[t]{2}{*}{ blaVEB } & VEB-F & ACCAGATAGGAGTACAGACATATGA & 727 & {$[8]$} \\
\hline & VEB-R & TTCATCACCGCGATAAAGCAC & & \\
\hline \multirow[t]{2}{*}{ blaDHA } & DHA-F & AACTTTCACAGGTGTGCTGGGT & 405 & [9] \\
\hline & DHA-R & CCGTACGCATACTGGCTITGC & & \\
\hline \multirow[t]{2}{*}{ blaCMY1 } & CMY-1-F & GCTGCTCAAGGAGCACAGGAT & 520 & [9] \\
\hline & CMY-1-R & CACATTGACATAGGTGTGGTGC & & \\
\hline \multirow[t]{2}{*}{ blaCMY2 } & CMY-2-F & TGGCCAGAACTGACAGGCAAA & 462 & [9] \\
\hline & CMY-2-R & TाTTCCTGAACGTGGCTGGC & & \\
\hline
\end{tabular}

Abbreviations: $\mathrm{ESBL}$, extended-spectrum $\beta$-lactamase; $\mathrm{F}$, forward; $\mathrm{R}$, reverse.

Table 2. Rates of ESBL-producing Escherichia coli and Klebsiella pneumoniae isolates

\begin{tabular}{|c|c|c|c|c|c|c|}
\hline \multirow{3}{*}{ Year } & \multicolumn{3}{|c|}{ E. coli } & \multicolumn{3}{|c|}{ K. pneumoniae } \\
\hline & \multirow{2}{*}{$\mathrm{N}$} & \multicolumn{2}{|c|}{ ESBL-producer } & \multirow{2}{*}{$N$} & \multicolumn{2}{|c|}{ ESBL-producer } \\
\hline & & $N$ & (\%) & & $N$ & $(\%)$ \\
\hline 2005 & 106 & 9 & 8.5 & 81 & 21 & 25.9 \\
\hline 2006 & 454 & 60 & 13.2 & 281 & 68 & 24.2 \\
\hline 2007 & 548 & 64 & 11.7 & 419 & 101 & 24.1 \\
\hline 2008 & 442 & 63 & 14.3 & 340 & 104 & 30.6 \\
\hline Total & 1,550 & 196 & 12.6 & 1,121 & 294 & 26.2 \\
\hline
\end{tabular}

Abbreviation: ESBL, extended-spectrum $\beta$-lactamase.

는 1,550 주 중 196 주(12.6\%)가, K. pneumoniae 1,121주 중 294 주(26.2\%)가 양성이었다(Table 2). ESBL 양성률은 연도별 로 E. coli는 8.5\%에서 $14.3 \%, K$. pneumoniae는 $24.1 \%$ 에서 $30.6 \%$ 의 범위 안에서 변화하였다. ESBL 생성 E. coli는 객담 과 농, 요 배양검체에서 각각 $34.9 \%, 17.1 \%, 10.6 \%$ 의 빈도로 분리되었고 $\mathrm{ESBL}$ 생성 $K$. pneumoniae는 농과 요, 객담 배양 검체에서 각각 $31.5 \%, 30.5 \%, 26.3 \%$ 의 빈도로 분리되었다. 이 중 농과 요 검체내 분리율이 두 균종 간에 통계적으로 유의한 차이를 나타냈다(Table 3).

\section{2. 항균제 감수성 검사 결과}

균주가 보관되었던 E. coli 196주와 K. pneumoniae 294주의 항균제 감수성 양상을 Vitek II 검사 결과로 살펴 보면 ampi- cillin, cefoxitin, ceftazidime, cefotaxime 및 cefepime에 대 한 E. coli의 내성률은 각각 $97.8 \%, 23.8 \%, 9.6 \%, 11.3 \%$ 및 $7.3 \%$ 이었고, K. pneumoniae의 내성률은 각각 $100 \%, 31.3 \%$, $18.9 \%, 13.6 \%$ 및 $12.5 \%$ 이었다. 분리된 균주는 모두 imipenem 에 감수성이었다.

\section{3. 분자생물학적 방법에 의한 내성 유전형 확인}

Vitek II system에 의해 ESBL검사 양성으로 나온 E. coli나 K. pneumoniae 균주들에서 플라스미드 DNA를 추출하여 $\mathrm{ESBL}$ 유전자 PCR을 시행한 후 그 산물을 염기순서분석한 결 과 E. coli는 46주 중 31주(67.4\%)가 $\mathrm{ESBL}$ 유전자를 보유하였 고 K. pneumoniae는 54주 중 41주(75.9\%)가 ESBL 유전자를 보유하였다. 
Table 3. Distribution of ESBL-producing Escherichia coli and Klebsiella pneumoniae isolates according to specimen type

\begin{tabular}{|c|c|c|c|c|c|c|c|}
\hline \multirow{3}{*}{ Specimen } & \multicolumn{3}{|c|}{ E. coli } & \multicolumn{3}{|c|}{ K. pneumoniae } & \multirow{3}{*}{$P$-value } \\
\hline & \multirow{2}{*}{ Total } & \multicolumn{2}{|c|}{ ESBL-producer } & \multirow{2}{*}{ Total } & \multicolumn{2}{|c|}{ ESBL-producer } & \\
\hline & & $N$ & $(\%)$ & & $\mathrm{N}$ & $(\%)$ & \\
\hline Urine & 782 & 83 & $(10.6)$ & 259 & 79 & $(30.5)$ & $<0.001$ \\
\hline Pus & 245 & 42 & $(17.1)$ & 162 & 51 & $(31.5)$ & $<0.022$ \\
\hline Sputum & 63 & 22 & (34.9) & 410 & 108 & (26.3) & $<0.242$ \\
\hline Blood & 276 & 13 & $(4.7)$ & 104 & 6 & $(5.8)$ & $<0.251$ \\
\hline Bile & 24 & 7 & $(29.2)$ & 22 & 7 & $(31.8)$ & $<1.000$ \\
\hline Bronchial washing & 10 & 3 & (30) & 51 & 10 & (19.6) & $<1.000$ \\
\hline Other & 142 & 22 & $(15.5)$ & 89 & 17 & $(19.1)$ & $<0.512$ \\
\hline
\end{tabular}

Abbreviation: ESBL, extended-spectrum $\beta$-lactamase.

Table 4. Plasmid-mediated AmpC $\beta$-lactamases in ESBL-producing Escherichia coli and Klebsiella pneumoniae isolates

\begin{tabular}{|c|c|c|c|c|c|c|c|}
\hline \multirow{2}{*}{ Organism } & \multirow{2}{*}{ ESBL type } & \multirow{2}{*}{$N$} & \multirow{2}{*}{$(\%)$} & \multicolumn{4}{|c|}{ Isolates with AmpC $\beta$-lactamase (N) } \\
\hline & & & & None & DHA-1 & CMY-1 & CMY-2 \\
\hline \multirow[t]{9}{*}{ E. coli } & CTX-M-14-like & 4 & $(12.9)$ & 4 & 0 & 0 & 0 \\
\hline & CTX-M-15-like & 11 & $(35.5)$ & 11 & 0 & 0 & 0 \\
\hline & CTX-M-14-variant & 3 & $(9.7)$ & 3 & 0 & 0 & 0 \\
\hline & CTX-M-15-variant & 9 & $(29.0)$ & 9 & 0 & 0 & 0 \\
\hline & CTX-M-14-variant + SHV-2a-like & 1 & $(3.2)$ & 1 & 0 & 0 & 0 \\
\hline & CTX-M-15-like + SHV-12-like & 1 & (3.2) & 1 & 0 & 0 & 0 \\
\hline & CTX-M-15-like + SHV-2a-variant & 1 & (3.2) & 1 & 0 & 0 & 0 \\
\hline & SHV-2a-like & 1 & (3.2) & 1 & 0 & 0 & 0 \\
\hline & Total & 31 & $(100)$ & 31 & 0 & 0 & 0 \\
\hline \multirow[t]{11}{*}{ K. pneumoniae } & CTX-M-14-like & 7 & $(17.1)$ & 5 & 2 & 0 & 0 \\
\hline & CTX-M-15-like & 1 & $(2.4)$ & 0 & 1 & 0 & 0 \\
\hline & CTX-M-14-variant & 3 & (7.3) & 3 & 0 & 0 & 0 \\
\hline & SHV-12-like & 19 & $(46.3)$ & 8 & 11 & 0 & 0 \\
\hline & SHV-12-variant & 3 & $(7.3)$ & 2 & 1 & 0 & 0 \\
\hline & CTX-M-14-like + SHV-12-like & 2 & (4.9) & 1 & 1 & 0 & 0 \\
\hline & CTX-M-15-like + SHV-12-like & 1 & (2.4) & 0 & 1 & 0 & 0 \\
\hline & CTX-M-14-like + SHV-12-variant & 1 & (2.4) & 0 & 1 & 0 & 0 \\
\hline & CTX-M-15-like + SHV-12-variant & 2 & (4.9) & 1 & 1 & 0 & 0 \\
\hline & SHV-12-like + CTX-M-14-variant & 2 & (4.9) & 0 & 2 & 0 & 0 \\
\hline & Total & 41 & $(100)$ & 20 & 21 & 0 & 0 \\
\hline
\end{tabular}

Abbreviation: ESBL, extended-spectrum $\beta$-lactamase.

염기순서분석으로 $\mathrm{ESBL}$ 유전형이 확정된 $\mathrm{ESBL}$ 보유균의 주된 유전형은 $\mathrm{CTX}-\mathrm{M}$ 과 $\mathrm{SHV}$ 형이었다. CTX-M과 $\mathrm{SHV}$ 형의 균종별 빈도는 E. coli 31 주 중 각각 $93.5 \%$ 와 $12.9 \%$ 이었고 $K$. pneumoniae 41 주 중 각각 $46.3 \%$ 와 $73.2 \%$ 이었다. 동일 균주 에서 $\mathrm{CTX}-\mathrm{M}$ 형과 $\mathrm{SHV}$ 형이 함께 나타난 것은 E. coli 3 주 (9.7\%)와 K. pneumoniae 8주(19.5\%)에서 관찰되었다(Table 4). VEB와 GES 유전자 PCR에 양성인 균주는 하나도 없었다. 검사대상 균주들의 $\mathrm{ESBL}$ 유전형에 대한 염기순서 분석 결과 E. coli 균주가 보유한 ESBL 유전형 중 CTX-M-15-like형이 13 주(41.9\%)로 가장 흔하였고 CTX-M-14-like형이 4주(12.9\%),
SHV-2a-like가 2주(6.5\%), SHV-12-like형이 1주(3.2\%) 있었 다(Table 4). K. pneumoniae 균주가 보유한 ESBL 유전형 중 SHV-12-like형이 24주(58.5\%)로 가장 흔하였고 CTX-M14-like형이 10주(24.4\%), CTX-M-15-like 형이 4주(9.8\%) 있었다(Table 4).

ESBL 생성 E. coli와 K. pneumoniae 균주들이 PABL을 함 께 보유하고 있는지를 조사하기 위해 PABL 유전자 검사를 시 행한 결과는 Table 4 와 같다. ESBL 생성 E. coli 균주 31 주 중 PABL PCR 검사에 양성인 균주는 하나도 없었다. Non-ESBL $\beta$-lactamase인 TEM-1 유전자를 보유한 E. coli 한 주에서 
Table 5. MICs $\left(\mu \mathrm{g} \cdot \mathrm{mL}^{-1}\right)$ for ESBL-producing Escherichia coli and Klebsiella pneumoniae isolates according to ESBL genotype

\begin{tabular}{|c|c|c|c|c|c|c|c|c|c|c|c|}
\hline \multirow{2}{*}{ Organism } & \multirow{2}{*}{ ESBL type } & \multirow{2}{*}{$\mathrm{N}$} & \multicolumn{3}{|c|}{ Ceftazidime } & \multicolumn{3}{|c|}{ Cefotaxime } & \multicolumn{3}{|c|}{ Cefoxitin } \\
\hline & & & Range & MIC50 & MIC90 & Range & MIC50 & MIC90 & Range & MIC50 & MIC90 \\
\hline \multirow{6}{*}{ E. coli } & CTX-M-14-like (3) & 7 & $\leq 1-4$ & $\leq 1$ & 4 & $\geq 256-\geq 256$ & $\geq 256$ & $\geq 256$ & $\leq 4-\geq 256$ & 16 & 32 \\
\hline & CTX-M-15-like (4) & 20 & $\leq 1-\geq 256$ & 256 & 256 & $\leq 1-\geq 256$ & $\geq 256$ & $\geq 256$ & $\leq 4-64$ & 16 & 32 \\
\hline & SHV-2a-like & 1 & $\leq 1$ & & & $\leq 1$ & & & 4 & & \\
\hline & SHV-12-like + & & & & & & & & & & \\
\hline & CTX-M-15-like & 1 & 256 & & & $\geq 256$ & & & 32 & & \\
\hline & $\begin{array}{l}\text { SHV-2a-like + } \\
\text { CTX-M-15-like }\end{array}$ & 1 & 256 & & & $\geq 256$ & & & 32 & & \\
\hline \multirow[t]{5}{*}{ K. pneumoniae } & CTX-M-14-like (1) & 10 & $2-\geq 256$ & 4 & $\geq 256$ & $\leq 1-\geq 256$ & 128 & $\geq 256$ & $\leq 4-\geq 256$ & $\leq 4$ & $\geq 256$ \\
\hline & CTX-M-15-like & 1 & $\geq 256$ & & & 16 & & & 256 & & \\
\hline & $\begin{array}{l}\text { SHV-12-like (3) } \\
\text { CTX-M-14-like (2) }\end{array}$ & 22 & $256-\geq 256$ & $\geq 256$ & $\geq 256$ & $\leq 1-\geq 256$ & 8 & $\geq 256$ & $\leq 4-\geq 256$ & 256 & $\geq 256$ \\
\hline & $\begin{array}{l}\text { + SHV-12-like (1) } \\
\text { CTX-M-15-like + }\end{array}$ & 5 & $4-\geq 256$ & $\geq 256$ & $\geq 256$ & $4-\geq 256$ & $\geq 256$ & $\geq 256$ & $\leq 4-\geq 256$ & 256 & $\geq 256$ \\
\hline & SHV-12-like (2) & 3 & $128-\geq 256$ & & & $8-\geq 256$ & & & $\leq 4-8$ & & \\
\hline
\end{tabular}

The numbers in parenthesis indicate the number of strains containing variants of each ESBL genotypes.

Abbreviations: ESBL, extended-spectrum $\beta$-lactamase; MIC50, minimum inhibitory concentration required to inhibit the growth of 50\% of organisms; MIC90, minimum inhibitory concentration required to inhibit the growth of $90 \%$ of organisms.

CMY-2-like가 나왔다. 염기순서분석으로 ESBL 유전자를 확 인한 K. pneumoniae 41균주 중 PABL을 보유한 21주(51.2\%) 모두가 DHA-1-like형 유전자로 확인되었다.

\section{ESBL 생성 E. coli와 K. pneumonia 균주들의 표현형적 특성}

$\mathrm{ESBL}$ 생성 E. coli와 $K$. pneumonia 균주들의 MIC를 CLSI 한천희석법으로 측정한 결과를 유전형별로 살펴보면 CTX-M15-like형 생성주는 cefotaxime과 ceftazidime에 대해 비슷한 $\mathrm{MIC}$ 를 보이거나 ceftazidime에 대해 더 높은 $\mathrm{MIC}$ 를 보이는 반면 CTX-M-14-like형 생성주는 ceftazidime보다 cefotaxime에 대해 훨씬 더 높은 $\mathrm{MIC}$ 를 보였다. SHV-12-like와 $\mathrm{CTX}-\mathrm{M}$ 형 ESBL을 함께 생성하는 균주들은 동일 유형의 CTX$\mathrm{M}$ 효소를 단독으로 생성하는 균주들보다 ceftazidime에 대해 상대적으로 높은 $\mathrm{MIC}$ 를 나타냈다(Table 5).

\section{고 찰}

국내 여러 병원에서 분리된 E. coli와 $K$. pneumoniae 임상 분리주 중 $\mathrm{ESBL}$ 생성주의 빈도는 E. coli는 9.2-14.2\%, $K$. pneumoniae는 17.7-30.0\%로 보고되어 왔다[10, 11]. 본 병원 의 $\mathrm{ESBL}$ 생성주의 연도별 평균 빈도가 $\mathrm{E}$. coli에서 $12.6 \%, \mathrm{~K}$. pneumoniae에서 $26.2 \%$ 로서, 국내 ESBL 양성률과 유사하였 고, 최근 $\mathrm{Ko}$ 등[10]이 보고한 $10.2 \%$ 와 $22.4 \%$ 의 빈도와도 유사
하였다. 3 년간 본 병원에서 분리된 균들의 $\mathrm{ESBL}$ 양성률은 $E$. coli는 8.5-14.3\%, K. pneumoniae는 24.1-30.6\%이었다. 각 연도의 빈도가 한국의 평균빈도와 유사한 범위 내에서 변동하 였지만 연도별로 $\mathrm{ESBL}$ 양성률이나 유전형의 빈도가 약간씩 달 라서, 동일한 병원 내에서도 연도별로 약간의 차이를 나타냄을 확인할 수 있었다.

한국에서 분리되는 E. coli에서 가장 유행하는 $\mathrm{ESBL}$ 형은 $\mathrm{SHV}-12$ 와 CTX-M형이었다[10, 12,13$]$. 최근 CTX-M형 특히 CTX-M-14과 CTX-M-15의 빈도가 높아지고 있어[8, 10-14] $\mathrm{ESBL}$ 분리 빈도의 증가는 CTX-M 효소의 파급에 기인한 것으 로 여겨지고 있다[11].

본 연구에서도 E. coli에서 SHV형보다 CTX-M형이 더 흔한 점은 비슷하였으나 SHV형 중 가장 흔한 $\mathrm{SHV}-12$-like형은 1 예였고, SHV-2-like와 SHV-2 variant형이 좀 더 많이 나온 것은 $\mathrm{Ko}$ 등[10]의 결과와 다른 점이었다. CTX-M형 중에서도 CTX-M-15-like형이 22주, CTX-M-14-like형이 7주로 CTX-M-15-like형이 CTX-M-14-like형보다 더 흔히 분리 된 점은 Ryoo 등[8]의 보고와 비슷하였으나, CTX-M-14가 많 았던 Lee 등[15], Ko 등[10], Song 등[11]과 다른 결과를 보였 다. 본 병원의 다년간 균주들이 보인 $\mathrm{ESBL}$ 유전형이 연도별로 빈도가 달랐으므로 연구자나 병원, 분리 연도에 따라 이런 차이 를 보이는 것은 자연스러운 현상으로 보인다.

한국에서 분리되는 $\mathrm{ESBL}$ 생성 $K$. pneumoniae 균종 중 가장 유행하는 $\mathrm{ESBL}$ 형은 SHV-12형이고[1, 8] 그 다음으로는 CTX$\mathrm{M}-14$ 형이나 CTX-M-3형 등이 흔한 것으로 보고되었다[8, 
15]. 본원에서도 SHV-12-like형이 가장 흔하고 CTX-M-14like형이 그 다음으로 흔히 분리되어 유사한 양상을 보였다.

본 연구에서 염기순서분석으로 $\mathrm{ESBL}$ 유전자가 확인된 $K$. pneumoniae 41주 중 21주(51.2\%)가 PABL을 함께 보유하여, 호흡기검체에서 분리된 $\mathrm{ESBL}-$ 생성 $K$. pneumoniae 균주들 중 53.5\%가 PABL을 함께 보유하였던 Yum 등[1]과 유사한 빈 도를 보였다. PABL의 유형으로 $\mathrm{CMY}-2$ 다음으로 $\mathrm{DHA}-1$ 대 립유전자가 흔하였던 Yum 등[1]의 결과와는 달리 본 연구에서 는 PABL을 함께 보유한 ESBL-생성 K. pneumoniae 균주 21 주 모두가 DHA-1-like형이었다. 본 연구에서 DHA-1 PCR에 양성인 $E$. coli는 한 주도 없었다.

국내에서 분리된 E. coli와 K. pneumoniae 균주들의 항균 제 감수성 검사결과를 살펴보면 E. coli는 cefotaxime에 대한 내성률이 10.6-11.1\%이었고 ceftazidime에 대한 내성률이 8.5$9.2 \%$ 이었다. K. pneumoniae는 cefotaxime에 대한 내성률이 13.9-14.6\%이었고 ceftazidim에 대한 내성률이 19.7-20.1\%이 었다[16, 17]. 본 연구에서도 cefotaxime과 ceftazidime에 대한 내성률이 E. coli는 각각 $11.3 \%, 9.6 \%$ 이고 K. pneumoniae는 각각 $13.6 \%$ 와 $18.9 \%$ 로 이와 비슷하였다.

본 연구에서 $\mathrm{ESBL}$ 보유균주들의 항균제 감수성 검사 결과를 단일한 $\mathrm{ESBL}$ 유전자를 가진 균들을 중심으로 살펴보았을 때 CTX-M-15-like형 생성주는 cefotaxime과 ceftazidime에 대해 비슷한 MIC를 보이거나 ceftazidime에 대해 더 높은 MIC 를 보이는 반면 CTX-M-14-like형을 생성하는 균주는 ceftazidime보다 cefotaxime에 대해 횔씬 더 높은 $\mathrm{MIC}$ 를 보인 점은 이전의 보고와 유사하였다[11, 18]. Bae 등[19]이 보고한 바와 같이 SHV-12-like형과 SHV-12-variant형을 생성하는 균주들은 cefotaxime보다 ceftazidime에 대해 더 높은 MIC를 보였다. SHV-12-like형과 CTX-M형 ESBL을 함께 생성하는 균주들은 동일 유형의 CTX-M형 효소를 단독으로 생성하는 균 주들보다 ceftazidime에 대해 더 높은 $\mathrm{MIC}$ 를 나타낸 점 역시 $\mathrm{Bae}$ 등[18]의 보고와 비슷하였다.

본 연구 결과 Vitek II system에서 ESBL 양성으로 나온 균 주의 67-75\%에서 ESBL 유전자형을 확인할 수 있었다. Vitek II system의 ESBL 검출민감도가 $91 \%$ 이고 특이도가 $85 \%$ 이어 서 $15 \%$ 의 위양성률이 있다고 한 Thomson 등[20]의 보고에 비 교해 볼 때 본 연구에서 유전자가 확인된 균주 수가 비교적 낮 다고 생각되었다. 그 이유를 추측해 볼 때 본 연구에서는 $\mathrm{SHV}$ 와 CTX-M, GES/IBC 및 VEB 유전자에 대해서만 검사하였기 때문에 그 외의 $\mathrm{ESBL}$ 유전자를 가진 균주들의 유전형이 검출 되지 못했을 가능성과 Vitek II system의 ESBL 검사상 위양성
일 가능성을 생각해볼 수 있었다. $\mathrm{AmpC}$ 유전자 역시 한국에서 흔히 보고되었던 $\mathrm{DHA}$ 와 $\mathrm{CMY}$ 형만 검사하여 다른 $\mathrm{AmpC}$ 유전 자 보유균을 놓쳤을 가능성이 있다고 생각된다.

또한 본 연구에서는 모집 균주가 시기적으로 고르게 분포되 지 못한 경향이 있으며 연구 기간이 연초부터 시작된 것이 아니 라 연도별 빈도를 살펴보기에는 미진하였다. 그러므로 장기간에 걸쳐 국내의 ESBL 양성률을 조사하려면 향후 연구할 균종과 지 역, 검체 수 및 검사대상 유전형의 종류를 확대하여 전국적인 ESBL 유전형 분포를 비교하는 추가 연구를 할 필요가 있다.

결론적으로 본 병원에서 3 년간 분리된 $\mathrm{ESBL}$ 생성 E. coli와 K. pneumoniae 균주에서 가장 흔한 유전형과 그 빈도를 살펴 보면 E. coli에서는 CTX-M형으로 63.0\%였고 K. pneumoni$\mathrm{ae}$ 에서는 $\mathrm{SHV}$ 형으로 $55.6 \%$ 였다. $6.5 \%$ 의 E. coli와 $14.8 \%$ 의 K. pneumoniae 균주가 CTX-M형과 SHV형 ESBL 유전형을 함께 보유하고 있었다. 흔한 유전형을 빈도별로 살펴보면 E. coli 에서는 CTX-M-15와 CTX-M-14, SHV-2a, SHV-12의 순이 었고 K. pneumoniae에서는 SHV-12, CTX-M-14, CTX-M15 의 순이었다. 본 연구에서 ESBL 생성 E. coli와 $K$. pneumoniae 균주들의 빈도와 유전형이 연도별로 약간씩 달랐기 때 문에 $\mathrm{ESBL}$ 생성 그람음성 장내세균의 빈도와 분포, 유전형의 변화 양상을 지속적으로 감시하면 이들의 확산을 억제할 대책 수립에 유용한 기초자료를 제공할 수 있을 것이다.

\section{요 약}

배경 : 한국 광주에서 3년간 수집된 extended-spectrum $\beta$-lactamase (ESBL) 생성 Escherichia coli 및 Klebsiella pneumoniae의 연도별 빈도와 유전형을 조사하고자 본 연구를 시행하였다.

방법 : 조선대학교 병원에서 2005년 9월 15일부터 2008년 9 월 14일까지 수집된 E. coli와 K. pneumoniae 임상분리주로 검 사하였다. 항균제 감수성 검사는 Vitek II 시스템(bioMérieux, $\mathrm{USA}$ )과 한천희석법으로 시행하였다. $\mathrm{ESBL}$ 및 $\mathrm{AmpC} \beta$-lactamase 유전자는 플라스미드 $\mathrm{DNA}$ 로 $\mathrm{PCR}$ 증폭하여 그 $\mathrm{PCR}$ 산물을 직접 염기순서분석하여 조사하였다.

결과 : ESBL 생성주의 빈도는 E. coli 1,550주 중 196주로 $12.6 \%$ 였고 K. pneumoniae 1,121주 중 294주로 26.2\%였다. ESBL 유전형의 염기순서분석결과 E. coli의 주된 형은 CTX$\mathrm{M}$ 형(93.5\%)과 $\mathrm{SHV}$ 형(12.9\%)이었고, K. pneumoniae의 주된 $\mathrm{ESBL}$ 형은 $\mathrm{SHV}$ 형(73.2\%)과 CTX-M형(46.3\%)이었다. E. coli 에서 가장 흔한 ESBL형은 CTX-M-15-like형이었고 그 다음 
은 CTX-M-14-like, SHV-2a-like, SHV-12-like형의 순이 었다. K. pneumoniae에서 가장 흔한 ESBL형은 SHV-12like형이었고 그 다음은 CTX-M-14-like, CTX-M-15-like 형의 순이었다. 염기순서분석으로 $\mathrm{ESBL}$ 유전형이 확인된 $K$. pneumoniae 41주 중 21주(51.2\%)가 DHA-1-like AmpC $\beta$ lactamase를 보유하였으나 $\mathrm{ESBL}$ 생성 E. coli 중 $\mathrm{AmpC} \beta-$ lactamase PCR에 양성인 균주는 없었다.

결론 : 본 연구에서 동정된 class A ESBLs 중 가장 흔한 $\mathrm{ESBL}$ 형은 E. coli에서는 CTX-M-15-like형이었고 $K$. pneumonia 에서는 SHV-12-like형이었다.

\section{참고문헌}

1. Yum JH, Kim S, Lee H, Yong D, Lee K, Cho SN, et al. Emergence and wide dissemination of CTX-M-type ESBLs, and CMY-2- and DHA-1-type AmpC $\beta$-lactamases in Korean respiratory isolates of Klebsiella pneumoniae. J Korean Med Sci 2005;20:961-5.

2. Song W, Lee KM, Kim HS, Kim JS, Kim J, Jeong SH, et al. Clonal spread of both oxyimino-cephalosporin- and cefoxitin-resistant Klebsiella pneumoniae isolates co-producing SHV-2a and DHA-1 $\beta$ lactamase at a burns intensive care unit. Int J Antimicrob Agents 2006;28:520-4.

3. National Committee for Clinical Laboratory Standards. Performance standards for antimicrobial susceptibility testing. Twelfth informational supplement, M100-S12. Wayne, PA: National Committee for Clinical Laboratory Standards, 2002.

4. Jeong SH, Bae IK, Kwon SB, Lee JH, Jung HI, Song JS, et al. Investigation of extended-spectrum $\beta$-lactamases produced by clinical isolates of Klebsiella pneumoniae and Escherichia coli in Korea. Lett Appl Microbiol 2004;39:41-7.

5. Saladin M, Cao VT, Lambert T, Donay JL, Herrmann JL, OuldHocine Z, et al. Diversity of CTX-M $\beta$-lactamases and their promoter regions from Enterobacteriaceae isolated in three Parisian hospitals. FEMS Microbiol Lett 2002;209:161-8.

6. Jeong SH, Bae IK, Kwon SB, Lee JH, Song JS, Jung HI, et al. Dissemination of transferable CTX-M-type extended-spectrum $\beta$-lactamase-producing Escherichia coli in Korea. J Appl Microbiol 2005; 98:921-7.

7. Machado E, Cantón R, Baquero F, Galán JC, Rollán A, Peixe L, et al. Integron content of extended-spectrum- $\beta$-lactamase-producing Escherichia coli strains over 12 years in a single hospital in Madrid,
Spain. Antimicrob Agents Chemother 2005;49:1823-9.

8. Ryoo NH, Kim EC, Hong SG, Park YJ, Lee K, Bae IK, et al. Dissemination of SHV-12 and CTX-M-type extended-spectrum $\beta$-lactamases among clinical isolates of Escherichia coli and Klebsiella pneumoniae and emergence of GES-3 in Korea. J Antimicrob Chemother 2005;56:698-702.

9. Pérez-Pérez FJ and Hanson ND. Detection of plasmid-mediated AmpC $\beta$-lactamase genes in clinical isolates by using multiplex PCR. J Clin Microbiol 2002;40:2153-62.

10. Ko KS, Lee MY, Song JH, Lee H, Jung DS, Jung SI, et al. Prevalence and characterization of extended-spectrum $\beta$-lactamase-producing Enterobacteriaceae isolated in Korean hospitals. Diagn Microbiol Infect Dis 2008;61:453-9.

11. Song W, Lee H, Lee K, Jeong SH, Bae IK, Kim JS, et al. CTX-M-14 and CTX-M-15 enzymes are the dominant type of extended-spectrum $\beta$-lactamase in clinical isolates of Escherichia coli from Korea. J Med Microbiol 2009;58:261-6.

12. Kim J, Lim YM, Rheem I, Lee Y, Lee JC, Seol SY, et al. CTX-M and SHV-12 $\beta$-lactamases are the most common extended-spectrum enzymes in clinical isolates of Escherichia coli and Klebsiella pneumoniae collected from 3 university hospitals within Korea. FEMS Microbiol Lett 2005;245:93-8.

13. Jeong SH, Bae IK, Lee JH, Sohn SG, Kang GH, Jeon GJ, et al. Molecular characterization of extended-spectrum $\beta$-lactamases produced by clinical isolates of Klebsiella pneumoniae and Escherichia coli from a Korean nationwide survey. J Clin Microbiol 2004;42:2902-6.

14. Park Y, Kang HK, Bae IK, Kim J, Kim JS, Uh Y, et al. Prevalence of the extended-spectrum $\beta$-lactamase and qnr genes in clinical isolates of Escherichia coli. Korean J Lab Med 2009;29:218-23. (박용정, 강 현경, 배일권, 김주원, 김재석, 어영 등. Escherichia coli의 Extended-Spectrum $\beta$-Lactamase 및 $q n r$ 유전자 보유 현황. Korean J Lab Med 2009;29:218-23.)

15. Lee SG, Jeong SH, Lee H, Kim CK, Lee Y, Koh E, et al. Spread of CTX-M-type extended-spectrum $\beta$-lactamases among bloodstream isolates of Escherichia coli and Klebsiella pneumoniae from a Korean hospital. Diagn Microbiol Infect Dis 2009;63:76-80.

16. Ko CS, Sung JY, Koo SH, Kwon GC, Shin SY, Park JW. Prevalence of extended-spectrum $\beta$-lactamases in Escherichia coli and Klebsiella pneumoniae from Daejeon. Korean J Lab Med 2007;27:344-50. (고지선, 성지연, 구선회, 권계철, 신소연, 박종우. 대전지역에서 분리된 Escherichia coli와 Klebsiella pneumoniae의 Extended-Spectrum $\beta$-lactamase 생성 
현황. Korean J Lab Med 2007;27:344-50.)

17. Kang JH, Bae IK, Kwon SB, Jeong SH, Lee J, Lee WG, et al. Prevalence of Ambler Class A extended-spectrum $\beta$-lactamase-producing Escherichia coli and Klebsiella pneumoniae isolates in Korea. Korean J Clin Microbiol 2005;8:17-25. (강지혜, 배일권, 권수봉, 정석훈, 이종 욱, 이위교 등. Ambler Class A Extended-Spectrum $\beta$-Lactamase 생 성 Escherichia coli와 Klebsiella pneumoniae의 국내 분리 현황. 대한임상 미생물학회지 2005;8:17-25.)

18. Bae IK, Lee YN, Jeong SH, Lee K, Lee H, Kwak HS, et al. High prevalence of SHV-12 and the emergence of CTX-M-12 in clinical isolates of Klebsiella pneumoniae from Korea. Int J Antimicrob Agents 2007;29:362-4.
19. Bae IK, Jeong SH, Lee K, Yong D, Lee J, Hong SG, et al. Emergence of CTX-M-12 and A Novel CTX-M Type Extended-Spectrum $\beta$-lactamase producing Klebsiella pneumoniae. Korean J Lab Med 2006;26:216. (배일권, 정석훈, 이경원, 용동은, 이종욱, 홍성근 등. CTX-M-와새로운 CTX-M형 Extended-Spectrum $\beta$-Lactamase 생성 Klebsiella pneumoniae의 출현. 대한진단검사의학회지 2006;26:21-6.)

20. Thomson KS, Cornish NE, Hong SG, Hemrick K, Herdt C, Moland ES. Comparison of Phoenix and VITEK 2 extended-spectrum- $\beta$ lactamase detection tests for analysis of Escherichia coli and Klebsiella isolates with well-characterized $\beta$-lactamases. J Clin Microbiol 2007;45:2380-4. 